\title{
Coolhunting e estudos de tendências aplicados à moda: modelo de segmentação estratégica
}

Coolhunting and trends studies applied to fashion: strategic segmentation model

\section{Nelson Pinheiro Gomes}

Doutor na Especialidade de Cultura e Comunicação pela Universidade de Lisboa. nelsonpinheiro@campus.ul.pt

\section{Maria Ana Vieira Lopes}

Mestre em Cultura e Comunicação pela Universidade de Lisboa. ma.vieiralopes@gmail.com

\section{Paulo Emanuel Alves}

Mestrando em Cultura e Comunicação na Universidade de Lisboa. p.alves@campus.ul.pt 


\section{Coolhunting e estudos de tendências aplicados à moda: modelo de segmentação estratégica ${ }^{1}$}

\section{Coolhunting and trends studies applied to fashion: strategic segmentation model}

\section{Nelson Pinheiro Gomes, Maria Vieira Lopes e Paulo Emanuel Alves}

\section{Resumo}

$\mathrm{O}$ presente artigo explora novas metodologias e conceitos no âmbito do desenvolvimento do produto e da marca de moda. Para tal, é sublinhada a importância dos Estudos de Tendências e do Coolhunting que indicam pistas sobre novas mentalidades e comportamentos do consumidor. As tradicionais abordagens ao sistema da moda revelam um fenómeno complexo onde por detrás do objeto, ou seja, da manifestação visível da moda, existe toda uma construção simbólica e uma relação de poderes que importa compreender e que dá origem a padrões e a novos gostos. Este trabalho começa por abordar o sistema da moda, para desenvolver de seguida os Estudos de Tendências e o Coolhunting. No fim, apresenta-se um modelo de aplicação dos Estudos de Tendências na área da Moda, com foco no potencial de segmentação de grupos e de públicos.

Palavras- chave: Estudos de Tendências; Coolhunting; Sistema da Moda.

\section{Abstract}

The present paper explores new methodologies and concepts that can help in the development of fashion products and brands. For such, we underline the importance of Trends Studies and Coolhunting, which provide insights on new consumer behaviors and mindsets. The traditional approaches to the fashion system reveal a complex phenomenon where behind the object, meaning the visible manifestation of fashion, exists a symbolic construction and power relation that originates new patterns and tastes. This work begins by approaching the fashion system, in order to proceed to Coolhunting and Fashion Studies. The objective is to present an application model based on Trends Studies for the fashion industry, with a focus on the potential for group and audience segmentation.

Keywords: Trends Studies; Coolhunting; Fashion System.

${ }^{1} \mathrm{O}$ texto escrito segue normas ortográficas de Portugal. 


\section{Introdução}

Com a atenção crescente a cair sobre conceitos como "slow fashion" ou o consumo consciente, a indústria da moda necessita de novas metodologias que permitam compreender o consumidor e gerir o sistema da moda. Os principais estudos sobre o processo de prescrição e o Coolhunting de moda têm dedicado especial atenção à manifestação física e visível da moda, mas ainda pouco às mentalidades que estão por detrás do sistema. O século XX e os primeiros anos do século XXI revelaram uma grande preocupação pelo estudo do sistema cultural da moda (BARTHES, 1999; BAUDRILLARD, 1998; BORDIEU, 2006; SIMMEL, 1957; DORFLES, 1990; BARNARD, 2002; CRANE, 2001). Todavia, permanece ainda muito por explorar a natureza simbólica, a estrutura e os processos associados à moda, enquanto fenómeno que surge na mente coletiva, fruto de estilos emergentes. Estes últimos são disseminados com base em relações de poder, na forma de objetos e de comportamentos.

À parte da necessária introdução ao conceito e à sociologia da moda, este ensaio não pretende desenvolver o tema do sistema da moda, mas sim compreender como o Coolhunting e os Estudos de Tendências podem contribuir para a indústria da moda, para além da definição de novos estilos e peças, através da identificação de públicos específicos e da compreensão das suas mentalidades e comportamentos. Neste sentido, importa traduzir as visões de alguns dos principais estudiosos de tendências (VEJLGAARD, 2008; HIGHAM, 2009; GLOOR e COOPER, 2007; RAYMOND, 2010), articulando-os com a disciplina específica do Coolhunting de Moda. Apesar de as duas áreas possuírem fortes pontos de contacto, ainda existe uma clara divisão entre o Coolhunting e o Coolhunting de Moda. Uma maior articulação entre ambos só pode trazer benefícios para o estudo da moda.

O ensaio começa por abordar temas introdutórios e teóricos, de modo a poder problematizar os mesmos na prática, identificando um potencial modelo para a segmentação. Os primeiros dois pontos do artigo apresentam as principais problemáticas da cultura e da sociologia da moda, bem como dos Estudos de Tendências e do Coolhunting. Com base nesta revisão literária, podemos problematizar os resultados do Coolhunting, de metodologias dos Estudos de Tendências e outras associadas e propor uma análise crítica dos públicos e dos grupos associados aos padrões de comportamento, determinando as suas mentalidades, necessidades, 
comportamentos e características identitárias. Estas informações acrescentam valor às ferramentas do marketing e dos estudos de mercado e apoiam a indústria da moda na compreensão do consumidor e do seu contexto., promovendo melhores estratégias de gestão, de marketing, de branding e de comunicação.

\section{Prescrição e Sistema da Moda}

\subsection{A Moda: Conceitos e principais autores}

A moda é um fenómeno complexo, inerente ao comportamento humano, e que engloba questões sociais, culturais e de comunicação. Como fenómeno intrinsecamente relacionado com o ser humano e com o comportamento dos indivíduos enquanto sociedade, a moda está presente nas mais pequenas manifestações culturais, identitárias, ideológicas e até religiosas. A moda é caracterizada por ser de carácter cíclico, assim como tendo uma forte componente de mudança que opera a par das alterações de mentalidade do seu tempo, produzindo transformações no vestuário, e em outros objetos, e no modo como os indivíduos se relacionam entre si. Ela recicla-se e reinventa-se de modo incessante e interminável, funcionando num amplo conjunto de códigos que contextualizam os seus significados numa determinada esfera espáciotemporal. $\mathrm{O}$ vestuário em si, desprovido do espaço e do tempo que contextualizam o indivíduo num determinado período temporal, não pode ser visto nos parâmetros do fenómeno da moda.

A moda relaciona-se com as formas de expressão de uma cultura, pertencendo a um complexo sistema de interações sociais. Sendo considerada um fenómeno proveniente da modernidade, a moda permite que sejam expressadas culturas, identidades e ideologias, tal como Jean Baudrillard sugere, num esquema de rutura, de progresso e de inovação (BAUDRILLARD, 1998, p.89). É através dos padrões comportamentais formados pela expressão individual e coletiva de uma sociedade que se identificam e consolidam mentalidades, ajudando a construir diversas realidades e identidades culturais. $\mathrm{O}$ modo como os indivíduos se relacionam com a moda constitui um reflexo das mentalidades de uma determinada sociedade.

Em termos sociológicos, culturais, e de comunicação, existem diversas análises e pontos de vista sobre a forma como a moda surge e se manifesta na interação entre 
indivíduos, dos quais importa salientar aqueles que de forma relevante nos esclareçam nestas questões.

De acordo com Georg Simmel, a moda não pode existir sem o desejo de integração e a necessidade de diferenciação; a distância que um indivíduo quer manter entre si e o todo é enfatizada quando esta questão passa pela diferenciação social. O autor entende a moda como a imitação de um determinado padrão, que satisfaz a necessidade de adaptação e diferenciação entre indivíduos (SIMMEL, 1997, p.189). Edward Sapir, assim como Georg Simmel, considera que a moda é parte do processo de diferenciação social, e acrescenta o fato de esta ser adotada por outro grupo que não aquele que a estabelece. Segundo o autor, houve desde sempre a propensão para a moda ser adotada pelos círculos cujo estatuto fosse inferior àqueles que impunham as modas (SAPIR, 1949, p.378).

Herbert Blumer entende a moda como um sistema de seleção coletiva e não como um processo de diferenciação social. $\mathrm{O}$ autor sugere que a moda entra em declínio não por ser abandonada pelo grupo que a concebe e adota, mas "porque dá lugar a um novo modelo em maior consonância com o gosto que se desenvolve" (BLUMER, 1969, p.282).

Ao considerar a produção de significados através do vestuário e da moda, podese afirmar que estes são importantes fontes de comunicação, estando relacionados com o modo como se vive em sociedade. Malcolm Barnard defende que o vestuário tem dois tipos de funções - funções materiais e funções culturais (BARNARD, 2002, pp.51-56) que representam, por um lado, o vestuário como algo que cobre e protege um corpo e, por outro, todos os significados que este pode produzir aliado a esse mesmo corpo.

Sobre os discursos da moda e no que diz respeito à linguagem escrita, Roland Barthes considera a moda na sua relação com o sentido. Segundo o autor, a peça de vestuário contém características formais (que a descrevem enquanto forma) e traços do "mundo" (BARTHES, 1981, p.34), ou seja, características que contextualizam e dão significado ao vestuário, formando discursos da moda.

$\mathrm{Na}$ relação entre esta produção de significados e o carácter cíclico e de reciclagem, de acordo com Jean Baudrillard, a moda está "sempre na base da abolição do passado: a ressurreição espectral das formas. (...) A sua própria existência [...] não é 
uma referência ao presente, mas uma reciclagem imediata e total" (BAUDRILLARD, 1998, p.88). Neste sentido, as mudanças da moda não derivam de uma revolução no seu signo e nos seus significados, mas numa transformação de signos que morrem e renascem num ciclo de renovação constante.

Por outras palavras, a moda consiste num processo social e comunicacional que tem como principal característica a mudança. Estas alterações são resultantes das oscilações do gosto, de mentalidades, de valores, de ideais e de preconceitos de uma cultura. É um fenómeno complexo, mas efémero, que influencia a construção de identidades, e constitui um fator determinante no modo como os indivíduos se relacionam entre si. A moda funciona em mecanismos cíclicos ou de reciclagem simbólica que acompanham o desenvolvimento das mentalidades. A moda necessita de mudança, de viver, de morrer e de renascer num curto espaço de tempo; celebra a paixão pelo novo e liberta-se do que não é recente.

\subsection{Moda: Sistema, Estrutura, Processo e Objeto}

O conceito de estrutura é o mais complexo nesta rede e modelo que pretendemos construir. Os estudos de cultura sempre dedicaram muita atenção à sua definição e ao seu papel, desde a questão da linguística (SAUSSURE, 2006) até ao próprio entendimento da cultura e das relações sociais. No âmbito dos Estudos de Tendências e da Moda, o conceito de estrutura assume também um papel de destaque, pois sugere construções do zeitgeist agregadas em mentalidades específicas. Em comparação com algumas das bases do estruturalismo, estas estruturas, na forma de tendências de mentalidade, são uma base para os códigos das relações entre indivíduos e grupos. Assim, os comportamentos dos indivíduos são explicados como produto destas estruturas sociais e culturais. Estas últimas são construções mentais que resultam da organização do zeitgeist em mentalidades específicas que permeiam o imaginário coletivo na forma de padrões. Não esquecer, contudo, que as estruturas são líquidas e podem até ser consideradas instáveis devido às várias mutações que vão sofrendo.

\footnotetext{
1 "Fashion is always rétro, but always in the basis of the abolition of the passé [the past]: the spectral and ressurection of forms. Its proper actuality [...] is not a reference to the present, but an imediate and total recycling” (BAUDRILLARD, 1998, p.88)
} 
Os vários fenómenos resultantes destas estruturas podem ser estudados pelas suas relações com outros fenómenos relacionados ou divergentes. Estes fenómenos são entendidos como manifestações das estruturas, ou objetos. Estes objetos são a manifestação visível das estruturas (um produto/serviço, um comportamento específico, um novo tipo de corte de cabelo, uma nova necessidade, entre outros). A passagem da estrutura e mentalidade para a manifestação ou objeto é executada pelo processo social, que traduz as mentalidades no imaginário coletivo para a realidade observável. Só podemos estudar as estruturas através destes objetos e manifestações.

Já o sistema representa as várias relações e ligações entre as estruturas, os processos e os objetos. Roland Barthes (1999) estudou o sistema da moda na perspetiva da semiótica e da linguagem dos vários discursos da moda, mas aqui falamos de sistema como uma natureza mais abrangente e plural. Tal como Nelson Gomes (2014, p.10) anteriormente referiu, esta delicada relação entre conceitos tem sido analisada principalmente ao nível do objeto, ao invés do sistema. Apesar de uma nova orientação que procura compreender o futuro da moda, este sistema ainda possuí faces visíveis e invisíveis complexas:

\begin{abstract}
A moda funciona em simultâneo como estrutura visível e invisível através do seu sistema e do seu objeto, sendo o último a face visível. O sistema da moda, um processo complexo e delicado, é o motor que traz vida à indústria do vestuário e é o verdadeiro gestor do ciclo do produto e da pertinência simbólica de cada peça. [...] O sistema de prescrição da moda no público é uma das questões mais complexas do fenómeno, pois é complicado determinar as várias redes de influências e os atores com mais poder - os criadores, as publicações periódicas de moda, as celebridades, ou até mesmo o público em geral e as tribos urbanas.
\end{abstract}

(GOMES, 2014, p. 12)

Desta forma, de modo a conseguir compreender este sistema, importa analisar e abordar com maior profundidade as relações de poder e o fenómeno da disseminação dos objetos e das mentalidades associadas à moda.

\title{
1.3. Relações de Poder na Moda
}

Pierre Bourdieu descreve-nos o campo social como:

um espaço multidimensional de posições tal que qualquer posição actual pode ser definida em função de um sistema multidimensional de coordenadas cujos valores correspondem aos valores das diferentes variáveis pertinentes: os agentes distribuem-se assim nele, na primeira dimensão, segundo o volume global do capital que possuem e, na segunda dimensão, segundo a composição do seu capital — quer dizer, segundo o peso relativo das diferentes espécies no conjunto das suas posses. (BOURDIEU, 1989: 135) 
O autor apresenta-nos dois conceitos importantes: os agentes e o capital. O campo social é introduzido como um espaço multidimensional de posições preenchidas por estes agentes localizados "segundo a composição do seu capital” (BOURDIEU, 1989, p.135). Este capital pode ser económico, cultural, social ou simbólico (BOURDIEU, 1989, p.134). O autor relaciona o capital simbólico com a fama e o prestígio:

O que existe é um espaço de relações o qual é tão real como um espaço geográfico, no qual as mudanças de lugar se pagam em trabalho, em esforços e sobretudo em tempo (ir de baixo para cima é guindar-se, trepar e trazer as marcas ou os estigmas desse esforço). Também as distâncias se medem nele em tempo (de ascensão ou de reconversão, por exemplo). (BOURDIEU, 1989, p.37)

A estrela, a "nova figura moderna" apresentada por Gilles Lipovetsky, existe neste espaço de relações produzida pelas indústrias culturais. Atualmente, estas estrelas são figuras que provêm de vários setores; são alvo de admiração por parte das massas e encontram-se no topo da escada social (LIPOVETSKY, 2010a, p.100). A cultura da celebridade está instalada, pois "todo o domínio da cultura transformou-se numa economia de vedetariado" (LIPOVETSKY, 2010a, p.101); é um reconhecimento no vazio de ação, onde o importante é ser conhecido.

As massas almejam ser como as celebridades. O desejo de ascender socialmente faz com que cresça a admiração por estas figuras; o que elas fazem, dizem, ou vestem é um exemplo para o resto dos indivíduos que se encontram nos degraus inferiores da escada social (VEJLGAARD, 2008, p.48-49). Estes são os Beautiful People que têm um poder de prescrição que não se limita apenas a uma área do social, pois tudo o que estas figuras realizam é, em última instância, uma inspiração e influenciam a forma como as massas interagem com o real. Os Beautiful People são os prescritores por excelência, cristalizando um dos extremos deste espaço relacional simbólico.

A indústria da Moda é uma expressão inquestionável das relações de poder simbólicas. O prescritor, como indivíduo, produz sempre um acréscimo de valor. As autoridades de prescrição assumem a forma de empresas, de marcas, de identidades ou de indivíduos. O poder simbólico destes prescritores define o nosso pensamento, o nosso estilo e o gosto. Estas autoridades validam o que é aceite. A sua influência é proporcional ao seu prestígio.

O indivíduo aspira pertencer ao mesmo grupo que estas autoridades; ter o que elas têm; viver e ser como elas; ambiciona ser uma autoridade no seu círculo. O desejo de 
pertença e o querer um estatuto mais alto tornam-se fatores importantes para compreender a forma como consumimos e como percecionamos o objeto da moda. Os prescritores ditam como se deve ser, agir e pensar. Mesmo que inconscientemente, todos somos afetados pelos Beautiful People. Em suma, as autoridades dominam as correntes de pensamento, de comportamento e de ação do mainstream. Os indivíduos procuram projetar perante o grupo social uma identidade, alicerçada nestas figuras simbólicas que validam a sua imagem. Desta forma, é imperativo compreender que a disseminação dos objetos e das mentalidades associadas à moda está sob a égide deste fenómeno no espaço de relação presente no campo social.

\section{Coolhunting e Tendências}

\subsection{Os Estudos de Tendências e o Coolhunting}

Os Estudos de Tendências são uma ferramenta importante para identificar comportamentos e analisar a evolução de mentalidades. Através destes estudos podem obter-se dados relevantes sobre o comportamento social que permitam um melhor entendimento das suas oscilações, levando a que se possa, no presente, melhor interpretar padrões e tendências.

De acordo com Henrik Vejlgaard, é a partir do estudo destes processos de estabelecimento e crescimento de uma tendência que podem surgir pistas que levem à identificação de tendências e, deste modo, a uma melhor compreensão do passado para procurar entender o presente (VEJLGAARD, 2008, p.27). Para o processo de identificação de tendências, é essencial construir o melhor entendimento possível do espírito do tempo e do momento em que vivemos. Torna-se necessário conhecer o zeitgeist. Henrik Vejlgaard sugere que:

\footnotetext{
By investigating the people who have started trends in the past, where trends frequently start, how trends emerge and grow, and why trends happen, we can define some rules for spotting trends.

(VEJLGAARD, 2008, p.2)
}

Através do processo de identificação, observação e da análise de Cool Examples - processo denominado Coolhunting -, torna-se possível a abertura a novas perspetivas, a novos padrões comportamentais, e à identificação de Tendências emergentes.

Com os Estudos de Tendências e o Coolhunting, de acordo com Henrik Vejlgaard (2008), podem ser retiradas pistas que ajudem na identificação de padrões de 
comportamento, e que levem a reconhecer manifestações de uma ou várias tendências e do seu potencial de crescimento. Com os estudos de tendências, ao observarem-se padrões de comportamentos que levam à identificação de tendências, pode ser gerada inovação que, aplicada a estratégias empresariais, vai ao encontro daquilo que o consumidor está recetivo, num determinado momento. Os Estudos de Tendências são uma importante ferramenta para a compreensão de mentalidades e, consequentemente, para a aplicação desses conhecimentos em diversas áreas de atividade.

\subsection{A moda e os Estudos de Tendências}

A moda é, antes de mais, uma tendência de estilo e de gosto, emergindo no seio do complexo sistema da moda, que opera de forma diferente das tendências de comportamento de consumo, ou até das político-institucionais, numa perpétua reciclagem dos signos e do código.

A moda possui um grande número de contradições e de paradoxos e é um dos expoentes máximos da sociedade de consumo. Tal como Henrik Vejlgaard refere, as mudanças no estilo e no gosto têm vindo a desenvolver-se há vários séculos, sendo que eram lentas a surgir e pertinentes durante mais tempo (VEJLGAARD, 2008, p. 194). Todavia, as mudanças começam a acelerar no século $\mathrm{XX}$, atingindo um ritmo exponencial nas primeiras décadas do século XXI. Os principais ensaios e reflexões sobre a moda são incapazes de abordar toda a rede de influência deste fenómeno social, bem como o seu potencial. Considerando a pluralidade de elementos no sistema da moda, é necessária uma visão multi-especializada, pois a moda está presente na música, na internet, na televisão, no cinema, e em tantos outros espaços de produção de cultural e de relação social. A moda, na sua relação com os Estudos de Tendências e como parte integrante deste campo disciplinar, é alvo recorrente de vários erros concetuais que prejudicam o estudo de ambos.

O Conceito de "Tendência de Moda" é um erro, pois a moda e a tendência são dois tipos de padrões. Se a Moda pode ser uma tipologia de tendência (de estilo e gosto), seria redundante dizer "tendência da moda", pois seria como dizer o padrão de um padrão. Neste sentido, e recuperando o argumento do ponto 1.2, importa novamente rever os conceitos associados ao campo do estudo da moda:

a) A estrutura na moda é a tendência de estilo e gosto. $\mathrm{O}$ estilo vem antes da moda. Isto era claro em séculos passados com o Barroco, o Rococó, entre muitos 
outros. Hoje, o estilo tem características diferentes e é mais líquido e plural, como é o caso do minimalismo que se tornou hiperbólico (vd. www.trendsobserver.com). Tal como Gillo Dorfles sugere, a um determinado estilo segue-se a moda desse estilo (DORFLES, 1990, p. 30), ou seja, primeiro tem de existir uma construção mental que permita o surgimento das manifestações, ou objetos.

b) O objeto da moda é manifestação da tendência de estilo e gosto num objeto, serviço ou comportamento, ou seja, um par de calças com um novo corte, um novo corte de cabelo, o ato de beber chá ao invés de café. Desta forma, estamos perante uma moda quando existe, durante um período limitado, um largo número de indivíduos ou grupos a adotar um novo comportamento ou objeto. Por outras palavras, não devemos dizer que as "calças skinny" são uma moda, pois um largo número de indivíduos a comprar e a vestir as ditas calças é que é uma moda (não confundir um padrão com um objeto).

Para os estudos de tendências, o estilo é equivalente a uma tendência de estilo e gosto, ou seja, um padrão de mentalidade. Esta é uma tipologia de tendências micro, abaixo dos paradigmas e das macro tendências que afetam, por sua vez, um largo número de setores, grupos e indivíduos durante um largo período de tempo. Conforme William Higham defende, com tempo é possível que uma micro tendência ganhe espaço e se transforme numa macro tendência (HIGHAM, 2009: 87), mas a moda mantém-se ligada ao seu sector de influência. A moda é um padrão de comportamento e de adoção de determinados objetos, com regras e uma natureza próprias, que resulta das tendências e de estilo e de gosto, podendo sempre atingir um largo número de indivíduos, mas mantendo-se limitada a determinados campos.

\subsection{Coolhunting e Coolhunting de Moda}

No exercício do estudo de tendências, importa considerar a observação dos trendsetters, os primeiros indivíduos a adotar o comportamento e o objeto das tendências, e dos seus seguidores no seu habitat natural. O Coolhunting é umas das principais ferramentas para compreender os comportamentos e a sua relação com as tendências. Apesar do processo possuir um carácter intuitivo, a compreensão de elementos culturais e sociais tornam-se necessários para fornecer as informações empíricas, de modo a discernir a natureza e o peso de uma moda e de uma tendência no tecido socioeconómico. O Coolhunter 
encontra-se no centro da renovação de símbolos e possui capacidade crítica de compreender e de observar sinais de mudança e de renovação do código de consumo específico de cada subcultura, a nível local e global. Por norma, são indivíduos com uma forte personalidade criativa e uma visão crítica e observadora, com uma capacidade excecional para identificar o que é Cool e compreender as várias linguagens sociais e a capacidade de comunicação dos grupos, partilhando estilos de vida e linguagens das várias tribos urbanas.

O Coolhunting pode ser operacionalizado e, com um mercado cada vez mais competitivo, torna-se essencial para as empresas poderem ter ferramentas de previsão e de compreensão das necessidades exatas e dos desejos dos consumidores. A observação e a análise das tendências podem fornecer pistas fundamentais para o desenvolvimento de novos produtos/serviços, estratégias e campanhas. Peter Gloor e Scott Cooper acrescentam que existem várias aplicações para o Coolhunting nos negócios, mas sublinham duas áreas em particular: a observação de mercados externos e o desenvolvimento de inovação interna (GLOOR e COOPER, 2007, p. 9).

Apesar das semelhanças com os Estudos de Mercado, o Coolhunting difere na perspetiva e no objetivo da análise. Todavia, a diferença é ainda maior no que diz respeito ao Coolhunting de Moda. Os primeiros desejam compreender o porquê das ações do consumidor no presente, de modo a obter pistas sobre o emergente para vislumbrar o futuro e a forma como esses comportamentos e ações se vão desenvolver nos próximos anos. O Coolhunting de Moda, possivelmente a primeira tipologia desta disciplina, preocupa-se com estilos e com novas demonstrações dos mesmos. A questão do visual profiling assume uma maior importância no Coolhunting de Moda, sendo que o registo visual nos bairros criativos, em guetos e em outros espaços criativos são uma base para a geração criativa de novas ideias. Mais do que uma procura sistemática de manifestações que confirmem um padrão de comportamento e de mentalidade, o Coolhunting de Moda procura a inspiração para o novo corte, a nova cor, o novo objeto da moda. Algo que será desconstruído e traduzido pelo criativo, dando origem as novas peças de vestuário, acessórios, calçado, joalharia e relacionados. Estes são os focos do Coolhunting de Moda, mas são concertados entre os agentes de poder da indústria. A inspiração vem do coletivo, mas a disseminação e o seu sucesso estão nas mãos dos agentes da indústria (das marcas e do designer ao editor das publicações periódicas de 
moda). Desta forma, compreende-se a concertação das coleções e das visualidades num determinado momento, dando origem a padrões de adoção a que chamamos moda.

Por sua vez, o Coolhunting de Moda articula-se com o Forecasting de Moda. Tal como Martin Raymond refere:

By definition and activity, trend forecasters are lifestyle detectives: men and women who spend their time detecting patterns or shifts in attitudes, mindsets or lifestyle options, that run against thinking or how people normally behave, live, dress, communicate and trade. (RAYMOND, 2010, p. 12)

Não obstante, importa também sublinhar que por vezes o Coolhunting e o Forecasting confundem-se e possuem objetos paralelos, até porque o Coolhunting de Moda possui objetivos de prospeção. Já Henrik Vejlgaard sugere que para um sociólogo de tendências, uma tendência não é algo que aconteceu, mas sim uma previsão de algo que vai ocorrer de uma certa forma e que será aceite pela população em geral (VEJLGAARD, 200, p. 7), confirmando a dificuldade recorrente que surge ao separar as duas disciplinas. Como tal, é importante reter que o Coolhunting surge como atividade de recolha e de observação e o Coolhunter é um intermediário entre a produção e o consumo de bens e serviços culturais. $\mathrm{O}$ forecasting propõe sugestões e visões com base nestes e em outros dados, como a atividade segundo a qual se faz uma previsão e identificação dos próximos padrões, texturas, cores, cortes e materiais a aplicar nos designs das estações seguintes. Por norma, este trabalho materializa-se num caderno de tendências. A WGSN - uma das mais cotadas empresas de Fashion Forecasting no mundo - possui uma já longa tradição no desenvolvimento de cadernos de tendências (vd. www.wgsn.com).

\section{Coolhunting e Arquétipos para a Indústria da Moda}

\subsection{Arquétipos: Aplicação dos Estudos de Tendências na Indústria da Moda}

Os Estudos de Mercado e outras disciplinas possuem ferramentas e metodologias específicas para a identificação de arquétipos de consumo, de públicostipo e de segmentos.

Neste ensaio, apresentamos o primeiro desenho do modelo "Arquétipos através de Tendências", ou Modelo AT, desenhado com o objetivo de identificar e segmentar arquétipos e grupos de indivíduos, de acordo com as suas receções dos comportamentos e dos objetos das tendências. Por outras palavras, o estudo da receção das mentalidades 
e dos seus consequentes padrões de comportamento permite a identificação de arquétipos de consumidores, em articulação com o conceito de tribos urbanas e a questão da tribalização cultural. Neste sentido, a metodologia do Coolhunting continua a ser a principal ferramenta capaz de estudar as relações entre público, objeto, comportamento e tendência. Ela permite não só identificar a manifestação da tendência, como analisar a sua disseminação e relação com manifestações semelhantes, bem como os públicos e os espaços envolvidos. Não obstante, existem outras metodologias que podem articular-se com o Coolhunting e os Estudos de Tendências, tais como, numa primeira fase, o estudo do meme cultural, da parasitação e dos tópicos do zeitgeist, a par de atividades de visual profiling; e, numa segunda fase, a gamification e o storytelling.

Importa sublinhar que este modelo não se limita apenas a um único campo, ou à análise de uma sub-cultura ou grupo específicos, mas para efeito deste trabalho, a atenção irá concentrar-se sobre o seu potencial no sector e na indústria da moda. Os pontos seguintes desconstroem as várias metodologias do modelo e a sua articulação.

\subsection{Identificação de Arquétipos: Receção de Mentalidades e Coolhunting}

Não é possível falar do Coolhunting como componente de um modelo, sem antes referir e exemplificar esta prática emergente. O Coolhunting tem sido muito criticado como prática "pouco científica" e séria. Isto advém do facto de a maioria dos indivíduos que diz praticar o Coolhunting não ter formação nem experiência para tal, resultando em dados recolhidos de forma aleatória e sem método, que muitas vezes apenas se resumem a "coisas giras". O Coolhunting, prática com ligações à etnografia, procura manifestações das tendências de mentalidade que sejam consideradas atrativas (que chamem a atenção), que sejam inspiradoras (que promovam ação por parte dos indivíduos e que inspirem ideias) e que tenham potencial de crescimento (replicação social). Tal como Carl Rohde sugere (vd. www.scienceofthetime.com), estes são os três elementos que se procuram nas manifestações, ou seja, nos Cool Examples. A estes, acrescentamos a necessidade de possuírem um carácter vanguardista.

Após se identificar um Cool Example, no mundo digital ou no terreno, o Coolhunter deve registar o mesmo (anotando o espaço onde foi identificado, tirando um registo visual e descrevendo os principais elementos do contexto em que o registo foi executado) para posteriormente descrever o mesmo, de modo a ser útil para a geração de inovação. Uma correta descrição do Cool Example deve possuir os seguintes 
elementos: a) Título que descreva sumariamente o conteúdo; b) Registo visual (com a indicação da fonte se for um registo de origem digital); c) Descrição do Cool Example, identificando as suas características e contexto; d) Justificação da natureza Cool (razão pelo qual se considera atrativo, inspirador e com potencial de crescimento); e) Identificação das principais pistas de inovação que podem ser transferidas; f) Identificação das principais tendências relacionadas; g) Identificação do Coolhunter ou do Analista de Tendências que executou o registo e a descrição. Esta é a metodologia empregue pela rede holandesa Science of the Time, uma das mais antigas redes de Coolhunting no mundo, e desenvolvida pela plataforma Trends Observer em Portugal.

No campo da moda, os registos podem não ser tão rigorosos, mas sublinhe-se que a mesma metodologia tem aplicação na identificação de tendências de estilo e gosto. Quando um largo número de manifestações, ou Cool Examples, sugerem comportamentos ou a geração de objetos semelhantes, então estamos perante a base para a identificação de uma tendência. Não obstante, no que diz respeito ao modelo proposto, o Modelo AT, o Coolhunting é a principal ferramenta, ou a primeira, na identificação de grupos segmentados. Tendo abordado a prática e o registo das manifestações que resultam do Coolhunting, importa agora compreender como pode ir para além dos seus objetivos iniciais. Ao terminar um, ou mais, Coolhunt, os Coolhunters e os Analistas de Tendências ficam na posse de um largo número de manifestações e dos seus contextos. Se, ao invés de abordar as mesmas com o objetivo de identificar tendências, o analista estudar os públicos, os indivíduos e os espaços associados a cada Cool Example, então ele poderá compreender quais os grupos e tipos de indivíduos mais recetivos a determinadas manifestações e qual foi o grau de receção por parte dos vários públicos. Por si só, estes dados e análises podem ser suficientes, mas em articulação com as seguintes ferramentas, gera-se um processo de confirmação múltipla das descobertas e dos segmentos, ou grupos, identificados.

\subsection{Teste de Publicidade pelo Meme e Parasitação Cultural}

O meme é um conceito desenvolvido e proposto por Richard Dawkins (1989). Este autor apresenta-nos este conceito como um elemento que replica informação através do processo de parasitação, num agente externo. Susan Blackmore defende que a abordagem ao meme deve ser sempre sob a perspetiva de um conjunto de informações que pode ser replicada (BLACKMORE, 1999). Atente-se na importância de que este 
elemento, ao ser portador de informação, modifica as mentes, sendo consequentemente um catalisador de mentalidades auxiliado pelo processo viral anteriormente mencionado (DENNETT, 1993).

A compreensão deste processo viral permite transformar o meme cultural num recurso crucial para a segmentação estratégica. Por um lado, com o meme conseguimos construir arquétipos de consumidor, após a identificação da parasitação que a marca imprime no campo social. Por outro lado, numa fase mais avançada, a introdução de processos de "memeficação" na comunicação vai facilitar a pregnância da marca no campo de relações no espaço social. Evidentemente que estamos a falar de processos complexos, no entanto, é possível ilustrar com um pequeno exercício para iluminar a influência que exercem no nosso inconsciente. Por exemplo, vamos ter em consideração a seguinte imagem:

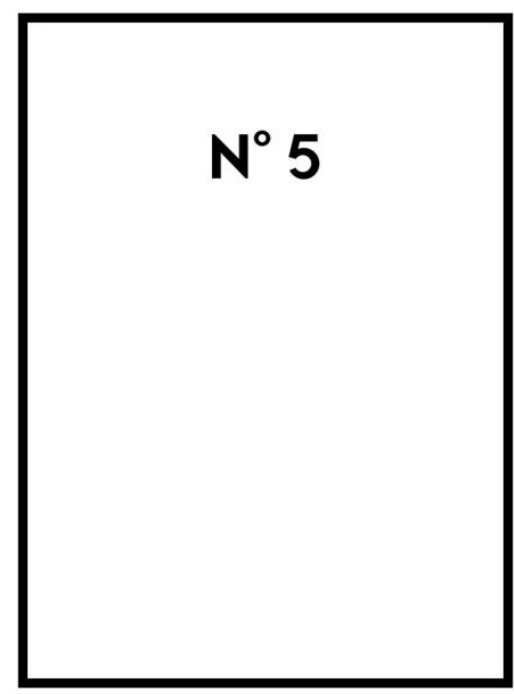

Figura 1: Imagem de Teste 1, imagem dos autores.

A questão importante é: o que é esta imagem? Responda a esta questão antes de prosseguir a leitura. Provavelmente a resposta automática do inconsciente afirma que a imagem é o perfume $\mathrm{N}^{\circ} 5$ da Chanel. Numa amostra de um grupo maioritariamente feminino (vinte e seis indivíduos) com idade média compreendida entre os 20-25, com frequência do ensino superior, a resposta foi Chanel $\mathrm{N}^{\circ} 5$. A imagem apresentada é, numa descrição objetiva, um retângulo com um " $\mathrm{n}$ 5 5 " alinhado ao centro vertical e posicionado acima do centro horizontal. Note-se que se confrontar o mesmo público apenas com a descrição, os resultados serão distintos do público que foi confrontado 
apenas com a imagem. O resultado perante a imagem é consequência de um processo de parasitação e este pequeno teste confirma a pregnância que o meme tem sobre a mente.

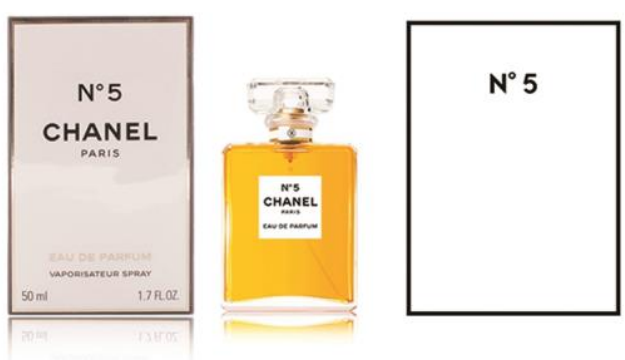

Figura 2 - Justaposição da fotografia documental do perfume Chanel No5 (à esquerda) e da imagem de teste um (à direita).

Repare-se na influência da representação do número cinco. Num contexto apropriado, como por exemplo uma publicação de moda, apenas o " $\mathrm{N}$ 5" é suficiente para evocar a marca. Daniel Dennett sugere que:

Two memes that happen to be physically tied together so that they tend always to replicate together, a fact that affects their chances. (DENNETT, 1993, 207)

Compreender a potencialidade na utilização conjunta de memes, o denominado de memplex (SPEEL 1995), permite uma comunicação mais eficaz e uma economia no discurso quer seja visual, ou escrito. Note-se que para uma aplicação mais precisa dos memes é necessário passar por uma fase de visual profiling que vamos abordar em seguida e articular os mesmos com outras ferramentas.

\subsection{Visual Profiling e Receção de Modas e Ondas}

A observação, análise e o estudo incessantes das indumentárias dos indivíduos de uma sociedade levam-nos a entender o modo como são criados e diferenciados grupos e tribos sociais, assim como nos ajuda a perceber a recetividade dos mesmos a modas e ondas. Ao atentar-se nas escolhas de vestuário dos indivíduos e nos momentos de adoção e de rejeição de uma onda e/ou de uma moda, está-se também a observar a formação de padrões - através da reunião de características visuais, físicas, comportamentais e de mentalidade que os dados observados nos facultam. Com estes dados é possível não só identificar grupos que respondem às mudanças cíclicas da moda 
de forma semelhante (constituindo um grupo), mas também um conjunto de fatores que, intrinsecamente ligados à indumentária, diferenciam um determinado grupo de outros, como valores, ideologias, crenças e atitudes.

Através do reunir de todas as características resultantes da observação e do estudo do modo como os indivíduos se apresentam, podem ser traçados perfis de indivíduos e de grupos, assim como de diferentes mentalidades, hábitos e modos de estar. Estes dados possibilitam também identificar e consolidar grupos de consumidores distintos, permitindo ao mercado delinear estratégias específicas em função das necessidades dos mesmos.

\subsection{Gamification e Storytelling}

Gamification e Storytelling são dois elementos importantes na construção de narrativas. Para compreender este dois conceitos de uma forma imediata, é necessário pensar num jogo de computador. O jogo tem sempre uma narrativa que pode ser linear ou não linear, no entanto, essa narrativa está sempre dependente de um modelo de recompensa, isto é, a progressão no jogo está limitado pelo sucesso de objetivos.

Jack Zipes sugere que o ser humano necessita de narrativas para a compreensão do mundo sensível (ZIPES, 2006). Note-se que a exploração desta necessidade em prol de uma melhor comunicação, assim como o meme, permite direcionar o processo de construção da publicidade. Devemos pensar que na aplicação dos memes nas narrativas

publicitárias estes tornam-se catalisadores de modelos de comportamento, enquanto conferem sentido ao real (ELIADE, 1963, p.10).

Tal como Gilles Lipovetsky refere, o hiperconsumidor adquire "produtos afetivos" onde está presente o recordar de emoções e de sensações já vividas (LIPOVETSKY, 2010a, p.63). Portanto, aliar esta construção de narrativas evocativas com a questão do jogo deve ser um foco importante no processo de execução de uma estratégia, de uma promoção ou no desenvolvimento de uma marca.

A Coca-Cola é uma marca onde esta construção é bastante evidente. Por exemplo, desde a campanha onde a marca introduziu nomes nas latas, que provocou uma procura do refrigerante numa obsessão individual pela procura do nome pretendido, elevando o objeto a um caracter de colecionador; até outra campanha onde usa uma narrativa com intuito de mostrar e repensar o conceito de família ao apelar a momentos evocativos. 
Gamification e Storytelling são ferramentas de desenvolvimento importantes pra o desenvolvimento de narrativas na indústria da moda, mas também podem ser úteis como testes de criatividade para a segmentação de públicos.

Com base no potencial já referido, ao expor um determinado número de indivíduos heterogéneos a um teste de criatividade onde se estuda a sua receção a técnicas de storytelling e de gamification, e onde se pede que resolvam problemas com base nestas ferramentas, é possível identificar padrões e pistas para a segmentação e a identificação de grupos e de respostas padrão.

Em conjunto, a articulação destas várias ferramentas, compondo o Modelo AT, permitem uma identificação, e confirmação sistemática entre si, de grupos, ou de segmentos, e da sua receção a comportamentos, objetos e mentalidades emergentes.

\section{Considerações Finais}

A moda é um dos fenómenos sociais mais complexos da nossa atualidade. Os seus códigos são tão líquidos que mudam a cada dia, de uma forma mais ou menos visível.

A prescrição social vertical proposta por G. Simmel (e também por T. Veblen) foi substituída pela horizontal e o duradouro pelo efémero. No entanto, é possível que já nem estas alterações façam sentido e daí o objeto e o objetivo deste ensaio em compreender as dinâmicas sociais nos padrões de comportamento e como a sua análise permite desenvolver novos métodos de segmentação e de interpretação de grupos sociais.

Neste sentido, este trabalho articulou algumas das visões mais reconhecidas sobre o estudo das tendências de mentalidade e da prática de Coolhunting, sublinhando o estado da arte e algumas das principais obras da área, sugerindo uma base capaz de aprofundar a geração de modelos e o desenvolvimento de estudos estratégicos para a indústria da moda, numa perspetiva inovadora próxima das Humanidades e das Ciências Sociais. A problemática por detrás da relação entre áreas dos estudos de tendências (incluindo o Coolhunting), do marketing e dos estudos da cultura, ou seja, das ciências do consumo e das humanidades, sublinha uma lacuna e uma nova perspetiva capaz de gerar novas soluções. $\mathrm{O}$ facto de estas relações interdisciplinares ainda serem imberbes revela o potencial das mesmas, complementando os estudos de outras disciplinas, tais como os estudos de mercado. 
Como resultado, importa sublinhar que as conclusões deste ensaio e do modelo gerado apontam para um possível alargamento do número de metodologias disponíveis aos profissionais e investigadores da indústria da moda e para a emergência da importância do estudo da receção e da parasitação simbólica no estudo do consumidor e no delinear estratégias de contacto com o consumidor. Aliás, a presente proposta conceptual apresenta-se como uma visão inovadora sobre a relação entre os vários elementos do sistema da moda.

Em larga medida, o modelo proposto, Modelo AT, lida com questões da receção de padrões de comportamento e de objetos frutos de mentalidade emergentes por parte de grupos, ou de tribos urbanas, e como estes descodificam a informação e os códigos culturais com base nos dados que foram recolhendo ao longo da vida e que fazem parte da sua memória e da memória coletiva. Ao compreender a receção das mentalidades, podemos segmentar com maior segurança os grupos, compreendendo os seus hábitos, necessidades e até os seus códigos sociais específicos, elementos da maior utilidade para a indústria da moda. Isto permite uma ativação direta do conhecimento na conceção e gestão da peça de moda ou de uma coleção. Por outras palavras, quão mais aprofundado é o conhecimento sobre o consumidor e os públicos mais próximos da marca, mais fácil é executar com segurança uma proposta criativa que vá ao encontro dos ditos públicos.

Este artigo apresenta-se, assim, como uma introdução ao potencial de segmentação presente nos Estudos de Tendências. Todavia, o modelo não se esgota na questão da segmentação e é necessário abordar e aprofundar futuramente articulações específicas com outras áreas, como o design thinking ou o design estratégico, de modo a permitir ativar novas aplicações do modelo. Permanece também por explorar, em sede de investigações futuras, o potencial do modelo na geração de pistas que podem ser aplicadas na construção de narrativas publicitárias, ou outras de comunicação estratégia, aplicando a questão da parasitação simbólica através do meme cultural. 


\section{Referências Bibliográficas}

BARNARD, Malcolm (2002). Fashion as Communication. London: Routledge.

BARTHES, Roland (1999) [1967]. Sistema da Moda. Tradução de Maria de Santa Cruz, Lisboa: Edições 70.

BAUDRILLARD, Jean (1998). Symbolic Exchange and Death. Tradução de Iain Hamilton Grant. Londres: Sage.

BLACKMORE, Susan (1999). The Meme Machine. Oxford: Oxford University Press.

BLUMER, Herbert (1969). "Fashion - From Class Differentiation to Collective Selection" in Sociological Quaterly 10.

CRANE, Diana (2001). Fashion and its Social Agendas. Chicago: University of Chicago Press.

BORDIEU, Pierre (2006) [1979]. A Distinção: Crítica Social do Julgamento. Traduzido por Daniela Kern e Guilherme Teixeira. São Paulo: Edições Zouk.

BOURDIEU, Pierre (1989). O Poder Simbólico. Tradução de Fernando Tomaz, Algés:

Difusão Editorial, S.A.

DAWKINS, Richard (1989). O Gene Egoísta. Tradução de Ana Paula Oliveira, Lisboa: Gradiva.

DENNETT, Daniel (1993). Consciouness Explained. Penguin Books.

ELIADE, Mircea (1963). Aspectos do Mito. Tradução de Manuela Torres, Lisboa: Edições 70.

DORFLES, Gillo (1990). Modas \& Modos. Tradução de J. Pinto Ribeiro, Lisboa: Edições 70. 
GLOOR, Peter e Scott Cooper (2007). Coolhunting: Chasing down the next big thing. New York: Amacom.

GOMES, Nelson P. (2014). "Branding de Moda na Hipermodernidade Líquida" in Revista Portuguesa de Marketing, $\mathrm{n}^{\circ} 32$, pp. 9-19.

LIPOVETSKY, Gilles (2010a). A Felicidade Paradoxal. Tradução de Patrícia Xavier, Lisboa: Ed.70.

LIPOVETSKY, Gilles; SERROY, Jean (2010b). A Cultura-Mundo. Resposta a uma sociedade desorientada. Tradução de Victor Silva, Lisboa: Edições 70.

HIGHAM, William (2009). The Next Big Thing. London: Kogan Page.

RAYMOND, Martin (2010). The Trend Forecaster's Handbook. London: Laurence King.

SAPIR, Edward (1949). "Fashion", in Selected Writings of Edward Sapir, ed. David Mandelbaum. Pp. 373-381. Berkeley: University of California Press.

SAUSSURE, Ferdinand (2006). Course in general linguistics. Tradução de Roy Harris, Illinois: Open Court Publishing.

SIMMEL, Georg (1957) [1904]. "Fashion" in American Journal of Sociology, pp. 541558.

VEJLGAARD, Henrik (2008). Anatomy of a Trend. New York: McGraw-Hill.

ZIPES, Jack (2006). Why fairy tales stick: The evolution and relevance of a genre. New York: Routledge. 